TITLE:

\title{
Small geographic variation in photoperiodic entrainment of the circannual rhythm in the varied carpet beetle, Anthrenus verbasci.
}

\section{AUTHOR(S):}

Matsuno, Tomoya; Kawasaki, Yuta; Numata, Hideharu

\section{CITATION:}

Matsuno, Tomoya ... [et al]. Small geographic variation in photoperiodic entrainment of the circannual rhythm in the varied carpet beetle, Anthrenus verbasci.. Zoological science 2013, 30(4): 304-310

ISSUE DATE:

2013-04

URL:

http://hdl.handle.net/2433/189716

RIGHT:

(C) 2013 Zoological Society of Japan 


\section{Small Geographic Variation in Photoperiodic Entrainment of the Circannual Rhythm in the Varied Carpet Beetle, Anthrenus verbasci}

Author(s): Tomoya Matsuno, Yuta Kawasaki, and Hideharu Numata

Source: Zoological Science, 30(4):304-310. 2013.

Published By: Zoological Society of Japan

DOI: http://dx.doi.org/10.2108/zsj.30.304

URL: http://www.bioone.org/doi/full/10.2108/zsj.30.304

BioOne (www.bioone.org) is a nonprofit, online aggregation of core research in the biological, ecological, and environmental sciences. BioOne provides a sustainable online platform for over 170 journals and books published by nonprofit societies, associations, museums, institutions, and presses.

Your use of this PDF, the BioOne Web site, and all posted and associated content indicates your acceptance of BioOne's Terms of Use, available at www.bioone.org/page/terms_of_use.

Usage of BioOne content is strictly limited to personal, educational, and non-commercial use. Commercial inquiries or rights and permissions requests should be directed to the individual publisher as copyright holder. 


\title{
Small Geographic Variation in Photoperiodic Entrainment of the Circannual Rhythm in the Varied Carpet Beetle, Anthrenus verbasci
}

\author{
Tomoya Matsuno ${ }^{1}$, Yuta Kawasaki ${ }^{1}$, and Hideharu Numata ${ }^{2 *}$ \\ ${ }^{1}$ Department of Biology and Geosciences, Graduate School of Science, Osaka City University, \\ Osaka 558-8585, Japan \\ ${ }^{2}$ Department of Zoology, Graduate School of Science, Kyoto University, \\ Kyoto 606-8502, Japan
}

\begin{abstract}
The circannual pupation rhythm of Anthrenus verbasci is entrained to an environmental cycle by changes in photoperiod. Exposure of larvae reared under short-day conditions to long days induced a clear phase delay of the circannual rhythm. There was no notable difference in the initial phase or period of the circannual rhythm among four geographically distinct populations of $A$. verbasci in Japan: Takanabe $\left(32.1^{\circ} \mathrm{N}\right)$, Osaka $\left(34.7^{\circ} \mathrm{N}\right)$, Sendai $\left(38.3^{\circ} \mathrm{N}\right)$, and Sapporo $\left(43.1^{\circ} \mathrm{N}\right)$ populations. The range of photoperiodic changes effective for phase delay in the circannual pupation rhythm was compared among the four populations. Although larvae did not show a typical threshold response, but responded quantitatively to the photophase duration in intermediate conditions, the critical daylengths were calculated as those under which the pupation was delayed by $50 \%: 12.8$ $\mathrm{h}$ in the Takanabe population, 13.2 $\mathrm{h}$ in the Osaka population, and $13.6 \mathrm{~h}$ in the Sendai and Sapporo populations. Thus, the critical daylength for entrainment of the circannual rhythm in $A$. verbasci was correlated to the habitat latitude, but the differences among the populations were much smaller than those reported in photoperiodism for induction of diapause in various insects. Consequently, the difference in the pupation time among the four geographic populations was very small under the natural photoperiod in Osaka at $20^{\circ} \mathrm{C}$, and absent under the natural photoperiod and temperature in Osaka. These results suggest that $A$. verbasci survives and successfully produces the next generation in different geographic regions without changing the parameters of the circannual rhythm.
\end{abstract}

Key words: critical daylength, insect, life cycle, phase delay, pupation

\section{INTRODUCTION}

Many organisms use a direct response to photoperiod, i.e., photoperiodism, to adapt to annual environmental changes (Nelson et al., 2010). Some organisms, however, adopt a circannual rhythm, an endogenous biological rhythm with a period of one year, for seasonal adaptations (Gwinner, 1986; Goldman et al., 2004). The period length of circannual rhythms is usually somewhat different from one year under constant conditions, although the period normally matches that of the geophysical year under natural conditions (Gwinner, 1986; Nisimura and Numata, 2003; Miyazaki et al., 2009a). In some animals, laboratory experiments have shown a change in photoperiod to be the most powerful zeitgeber for circannual rhythms (e.g., Goss, 1969; Gwinner, 1977; Randall et al., 1998; Nisimura and Numata, 2003; Monecke et al., 2009), but these responses to photoperiod reset the phase of the circannual rhythm and are different from classical photoperiodism (Miyazaki et al., 2005, 2007; Monecke

\footnotetext{
* Corresponding author. Tel. : : +81-75-753-4073;

Fax : +81-75-753-4113;

E-mail: numata@ethol.zool.kyoto-u.ac.jp
}

doi:10.2108/zsj.30.304 et al., 2009).

Species distributed in geographically distinct areas are exposed not only to different climatic conditions, but also to different photoperiods in their natural habitats. Therefore, these species should have geographic variation in their photoperiodism to enable fine-tuning of seasonal events to local climatic conditions. In fact, geographic variation in the critical daylength has been shown in many insects (Danilevskii, 1965; Beck, 1980). In species that have responses to photoperiod for entrainment of their circannual rhythms, geographic variation may also exist, because they are also exposed to different climatic conditions and photoperiods. However, geographic variation in circannual rhythms has been examined only in some vertebrates (e.g., Ward and Armitage, 1981; Joy and Mrosovsky, 1982; Gwinner et al., 1983; Gwinner, 1991; Helm and Gwinner, 2001; Helm et al., 2009). Moreover, no study has examined the geographic variation in the critical daylength for entrainment of circannual rhythms.

The varied carpet beetle, Anthrenus verbasci, is widely distributed in temperate regions, and shows a circannual rhythm (Blake, 1958, 1959; Nisimura and Numata, 2001). Depending on the climate and nutritional conditions, the life cycle of this species varies from one to several years, but 
pupation always occurs in spring (Blake, 1958, 1959; Nisimura and Numata, 2001; Miyazaki et al., 2009a). The period of the circannual rhythm is shorter than 12 months under a constant photoperiod (Nisimura and Numata, 2001). After the summer solstice, larvae set their phase by the decrease in photoperiod across the critical value and synchronize to the annual cycle (Nisimura and Numata, 2003; Miyazaki et al., 2006; Miyazaki and Numata, 2009). Thus, the phase setting induced by the decrease of photoperiod in late summer and autumn is important for the synchronization of the circannual rhythm with the natural annual cycle. In the present study, to clarify whether geographic variation exists in the circannual rhythm of this species, we examined the differences in the period length of the rhythm and the responsiveness to photoperiod for phase setting among four geographically distinct populations in Japan. We then reared these populations under natural photoperiod at a constant temperature and under natural photoperiod and temperature in Osaka to examine whether populations with different geographic origins pupate at the correct time of year.

\section{MATERIALS AND METHODS}

Adults of $A$. verbasci were collected in Takanabe $\left(32.1^{\circ} \mathrm{N}\right.$, $\left.131.5^{\circ} \mathrm{E}\right)$, Osaka $\left(34.7^{\circ} \mathrm{N}, 135.5^{\circ} \mathrm{E}\right)$, Sendai $\left(38.3^{\circ} \mathrm{N}, 140.9^{\circ} \mathrm{E}\right)$ and Sapporo $\left(43.1^{\circ} \mathrm{N}, 141.3^{\circ} \mathrm{E}\right)$, in April-July in 2009 (Fig. 1). These adults and their eggs were kept under conditions of $16 \mathrm{~h}$ light and $8 \mathrm{~h}$ darkness (LD 16:8) at $25 \pm 1^{\circ} \mathrm{C}$, and larvae within a week after hatching were used for the experiments. Larvae of the second laboratory generations were also used. The artificial constant photoperiod was produced using white fluorescent lamps (Panasonic, Osaka) and timers (Omron, Kyoto), and the light intensity in the photophase was about $0.9 \mathrm{~W} / \mathrm{m}^{2}$. Some larvae were kept continuously under LD $12: 12$ at $20 \pm 1^{\circ} \mathrm{C}$. The other larvae were exposed to LD 13:11, LD 13.5:10.5, LD 14:10, LD 15:9 or LD $16: 8$ at $20^{\circ} \mathrm{C}$ for 12 weeks after hatching and transferred to LD 12:12. For rearing under natural photoperiod at $20^{\circ} \mathrm{C}$, an incubator was placed beside a window in the laboratory. For rearing under natural photoperiod and temperature, a cage was placed outdoors on the campus of Osaka City University. In all experiments, the relative humidity was maintained at approximately $66 \%$ with a saturated solution of $\mathrm{NaNO}_{2}$, and dried bonito powder and dried yeast were provided as larval food. Pupation of larvae was recorded each week (see Nisimura and Numata, 2001, 2003 for details).

\section{RESULTS}

When larvae were kept continuously under LD 12:12, pupation occurred synchronously and showed a periodic pattern in the four populations (Fig. 2). Most larvae pupated 20-29 weeks after hatching, and were designated as the first group, which had a median larval duration of 24 weeks in the Takanabe and Sendai populations, and 25 weeks in the Osaka and Sapporo populations. Thus the difference among the four populations was only one week, although the differences were statistically significant between some of the populations. Some larvae pupated 54-74 weeks after hatching, and were the second pupation group, which showed differences in their median larval durations of only $0-1.5$ weeks, with no significant differences in larval duration among the four populations. The intervals between the medians for the first and second groups were 39.0-41.5 weeks.

An exposure to a longer photophase for 12 weeks significantly delayed pupation in the first group (Figs. 3, 4). The magnitude of the delay depended both on the photophase duration and the geographic population. In all four populations, however, LD 15:9 and LD 16:8 delayed pupation significantly more than LD 13:11 and LD 13.5:10.5. Thus, exposure to a longer photophase caused a clear phase delay of the circannual rhythm. The maximum delays were 9-10 weeks in the four populations. Figure $5 \mathrm{~A}$ shows the relationship between the photophase duration and the degree of phase delay, regarding the phase delay in LD 16:8 from the pupation peak under continuous LD $12: 12$ as $100 \%$. Under intermediate conditions of LD 13:11 and LD 13.5:10.5, the degree of phase delay was different among the geographic

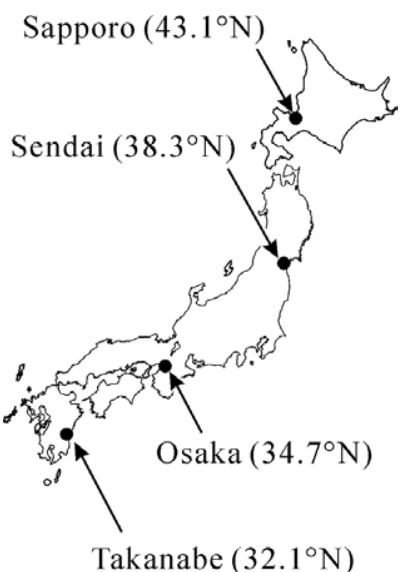

Fig. 1. Collecting sites of Anthrenus verbasci for the present study.

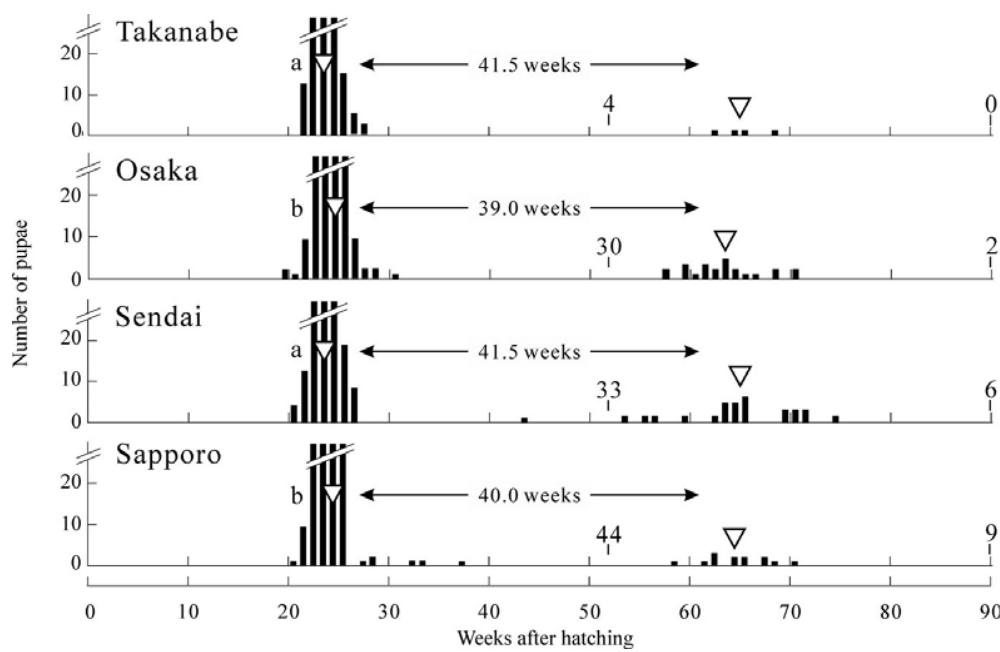

Fig. 2. Circannual pupation rhythm under constant short-day conditions (LD $12: 12,20^{\circ} \mathrm{C}$ ) in Takanabe, Osaka, Sendai, and Sapporo populations of Anthrenus verbasci. Each numeral above a vertical line indicates the number of insects remaining as larvae after 52 and 90 weeks. The triangle indicates the median of each pupation group. Significant differences in pupation times are shown as different letters for the first pupation groups in each population (Steel-Dwass test; $P<0.05$ ). There are no significant differences in the second pupation (KruscalWallis test, $P>0.05$ ). For the exact number of pupae in the first pupation group, see Figs. 3 and 4 

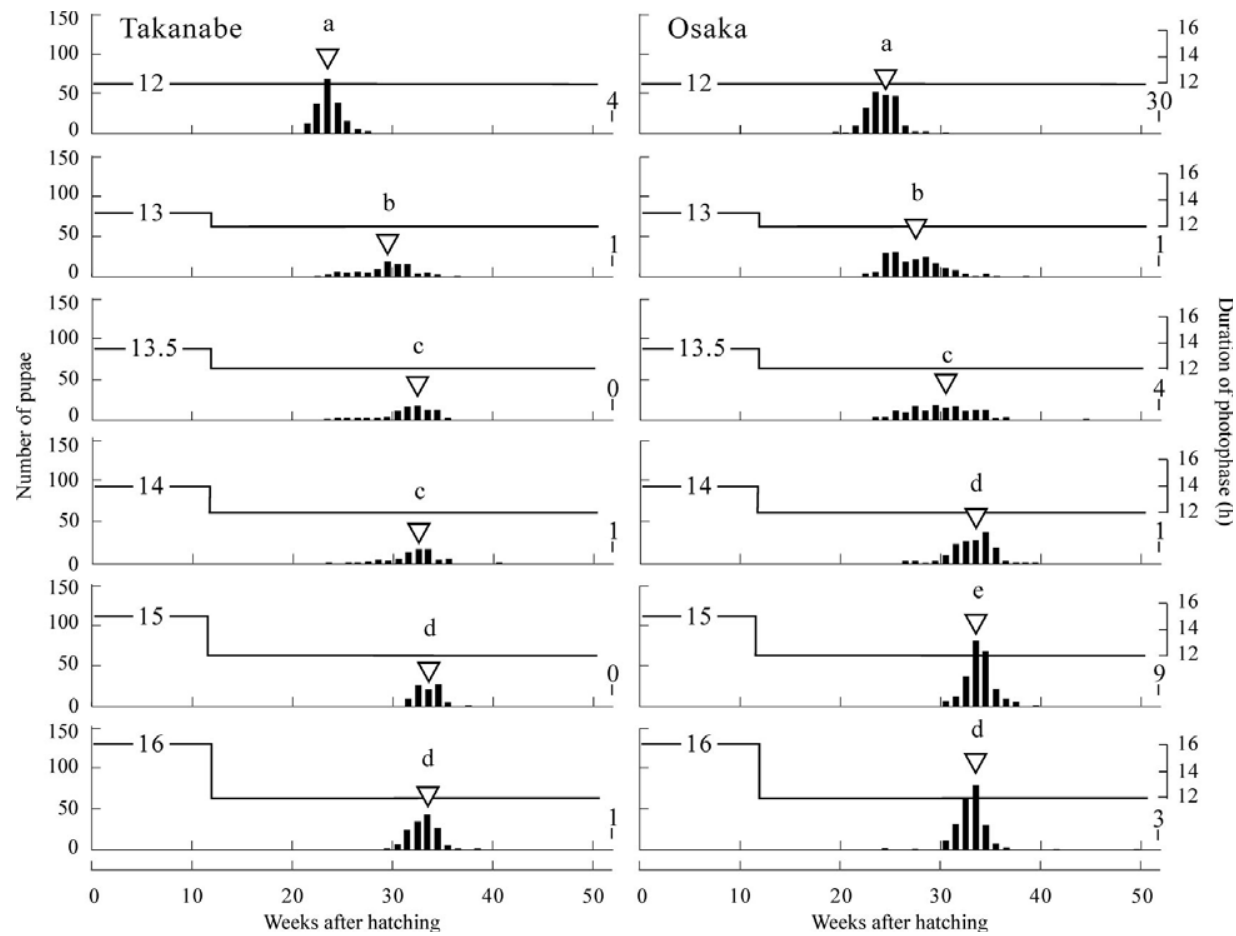

Fig. 3. Effects of photoperiodic changes on the circannual pupation rhythm in Takanabe and Osaka populations of Anthrenus verbasci at $20^{\circ} \mathrm{C}$. The solid line in each panel indicates the duration of the photophase (right axis). Each numeral above a vertical line indicates the number of insects remaining as larvae after 52 weeks. The triangle indicates the median of the first pupation group. Significant differences in pupation times are shown as different letters in each population (Steel-Dwass test, $P<0.05$ ).
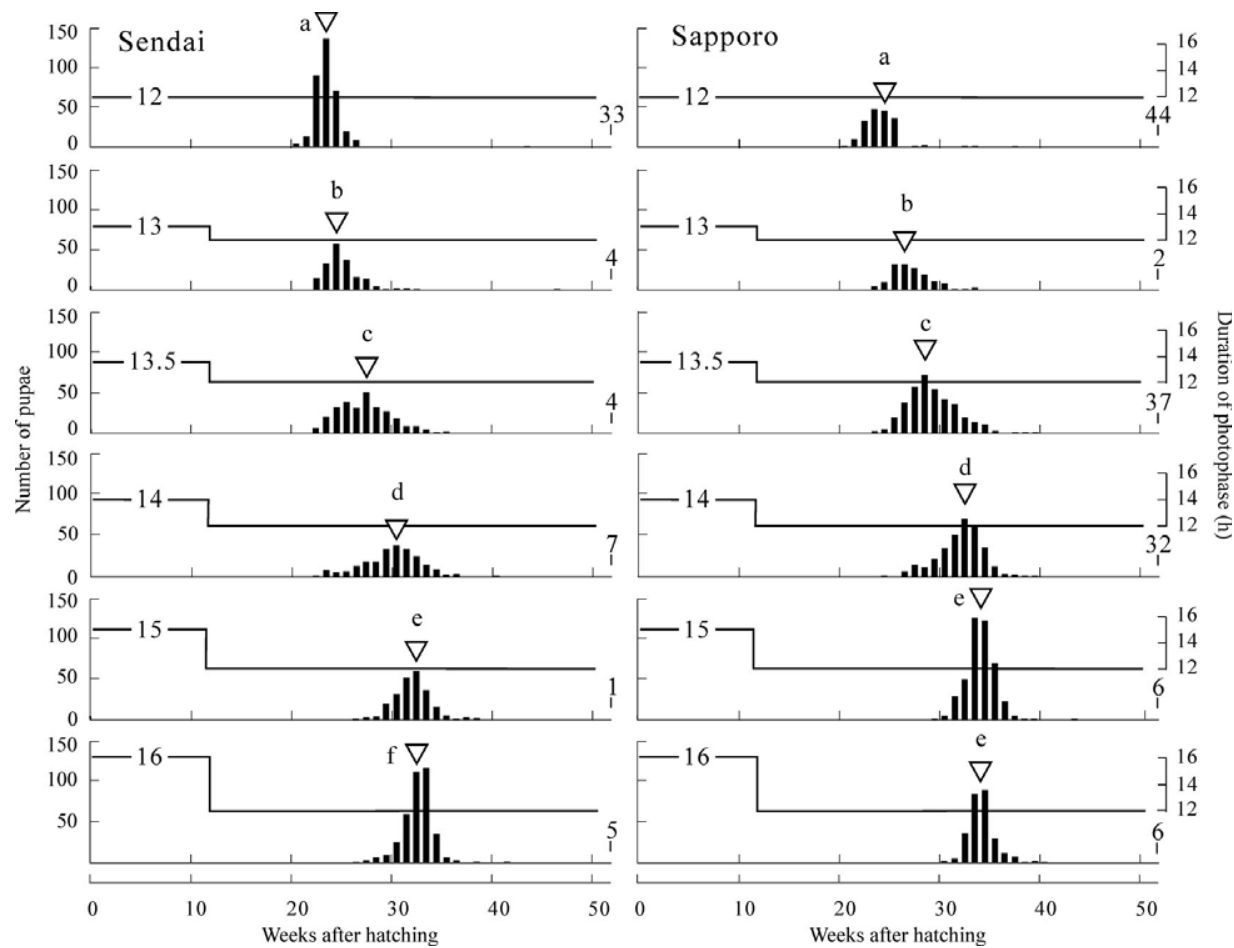

Fig. 4. Effects of photoperiodic changes on the circannual pupation rhythm in Sendai and Sapporo populations of Anthrenus verbasci at $20^{\circ} \mathrm{C}$. The solid line in each panel indicates the duration of the photophase (right axis). Each numeral above a vertical line indicates the number of insects remaining as larvae after 52 weeks. The triangle indicates the median of the first pupation group. Significant differences in pupation times are shown as different letters in each population (Steel-Dwass test, $P<0.05$ ). populations. Under these conditions, the phase delay was large in the Takanabe population, moderate in the Osaka population, and small in the Sendai and Sapporo populations. Although these were not typical threshold responses, as they responded quantitatively to the photophase duration in intermediate conditions, we calculated the critical daylength as that under which the pupation was delayed by $50 \%$, i.e., $12.8 \mathrm{~h}$ in the Takanabe population, $13.2 \mathrm{~h}$ in the Osaka population, and $13.6 \mathrm{~h}$ in the Sendai and Sapporo populations (Fig. 5B). The critical daylength showed a geographic cline and was correlated to the habitat latitude among the Takanabe, Osaka, and Sendai populations, although it was the same between Sendai and Sapporo populations despite the $4.8^{\circ}$ latitude difference.

Under the natural photoperiod in Osaka at $20^{\circ} \mathrm{C}$, most larvae of the Takanabe population pupated in February, with the median in the third week in February. Pupation of the Osaka population occurred significantly earlier than that of the Takanabe population, and larvae of the Sendai and Sapporo populations pupated significantly earlier than larvae of the other two populations, and pupation was more synchronous in the southern populations (Fig. 6). However, the difference in the median pupation time was only two weeks between the earliest and latest populations. In contrast, the proportion of the insects that pupated within a year was considerably different among the four populations. It is not possible to rigorously compare these values among the populations, as the larvae of the Sapporo population were placed under the experimental conditions approximately one month later than those of the other three populations. However, there was a tendency for a greater proportion of insects to pupate in a year in southern populations. 

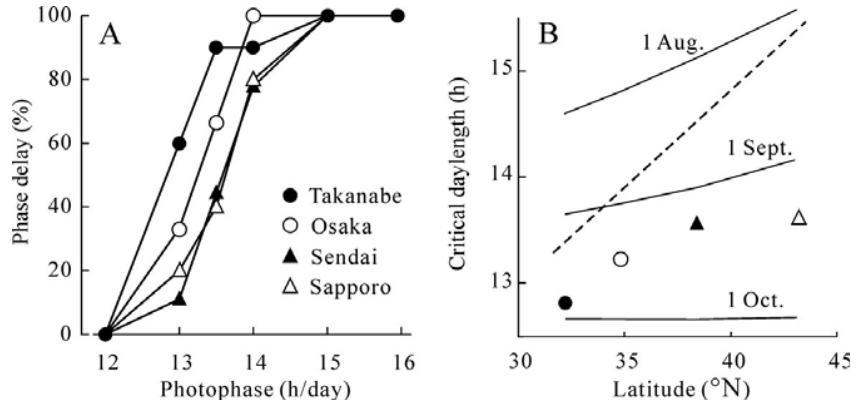

Fig. 5. The relationships between the photophase and the degree of phase delays (A) and between the latitude and the critical daylength for phase delay (B) in the circannual rhythm of Takanabe, Osaka, Sendai, and Sapporo populations in Anthrenus verbasci at $20^{\circ} \mathrm{C}$. Phase delays were calculated from the median larval durations of the first pupation group when larvae were exposed to various photoperiods for 12 weeks after hatching compared to the larval duration under continuous LD 12:12. The phase delay in LD 16:8 was regarded as $100 \%$, and the critical daylength corresponds to the $50 \%$ phase delay. The broken line designates the critical daylength for induction of larval diapause in Chilo suppressalis at $25^{\circ} \mathrm{C}$ (Kishino, 1970), and the solid lines show the natural daylength including civil twilight on the first day of August, September and October (National Astronomical Observatory of Japan, 2012).

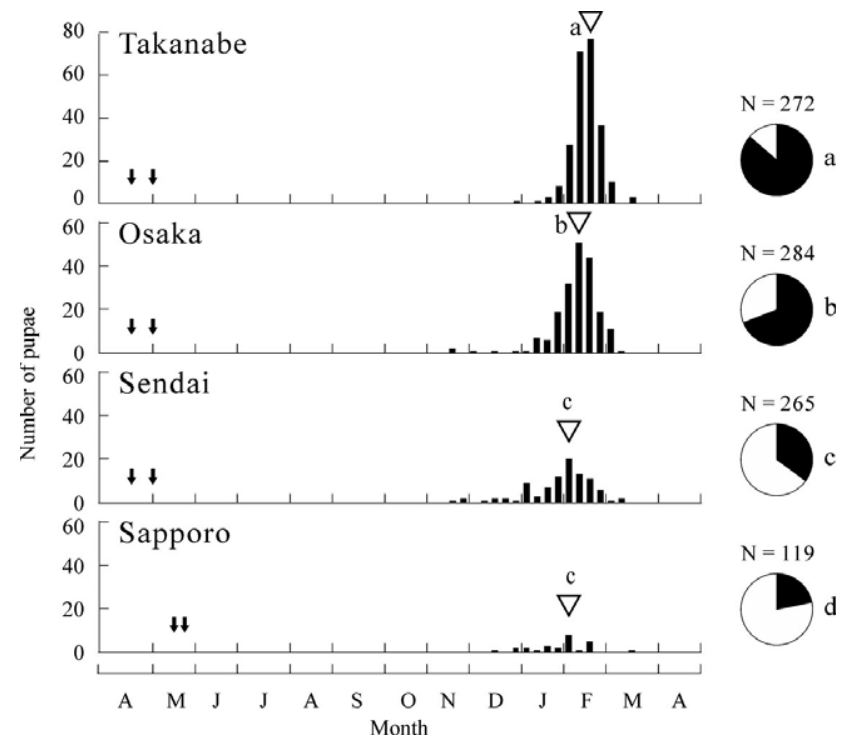

Fig. 6. Pupation under natural photoperiod in Osaka at $20^{\circ} \mathrm{C}$ of Takanabe, Osaka, Sendai and Sapporo populations in Anthrenus verbasci. In each population, newly hatched larvae were placed to the experimental conditions twice (arrows), and triangles show median values. Significant differences in pupation times are shown as different letters (Steel-Dwass test, $P<0.05$ ). The fan diagrams show the proportion of insects that pupated in a year (black areas, the insects that pupated before $25 \mathrm{March}$; white areas, the remaining larvae on 25 March). Proportions with the same letter are not significantly different (Tukey-type multiple comparison for proportions, $P>0.05$ ).

Under the natural photoperiod and temperature in Osaka, most larvae pupated in April and the median pupation times were the second week in April in all four populations, although there were statistically significant differences between the Takanabe/Sendai and Osaka/Sapporo populations (Fig. 7). Under these conditions, most insects pupated within a year in all of the four populations.

\section{DISCUSSION}

There was no notable difference among the four geographic populations in either the initial phase or the circannual period under constant short-day conditions. In the present and previous experiments under constant LD 12:12 at $20^{\circ} \mathrm{C}$ in Osaka populations of $A$. verbasci, the median larval duration of the first pupation group was $25.0 \pm 1.0$ weeks (mean \pm S.D., $n=15$ ), and the interval between the medians for the first and second groups was $38.9 \pm 2.4$ weeks (Fig. 2; Nisimura and Numata, 2001, 2002, 2003; Miyazaki et al., 2005, 2007, 2009a, b; Miyazaki and Numata, 2009, 2010). In the three populations with geographically different origin, the median larval duration of the first pupation group was 24-25 weeks, and the interval between the medians for the first and second groups was 40.0-41.5 weeks (Fig. 2). These values are similar to those in the Osaka populations.

In the yellow-bellied marmot, Marmota flaviventris, the circannual phase of food consumption under a constant LD 12:12 was earlier by two months in a lowland population than in a montane population, although no prominent difference was observed in the circannual period between the two populations. This difference corresponds to the difference in the aboveground activities between the two populations (Ward and Armitage, 1981). The stonechat, Saxicola torquata, shows a circannual rhythm in molting, reproduction and migration (Gwinner and Dittami, 1990, Gwinner, 1991; Helm, 2006). The period of the rhythm for testicular development under a constant photoperiod of LD 12.25: 11.75 was not significantly different between the European subspecies, S. $t$. rubicola, and the African subspecies, $S$. $t$. axillaris (Gwinner, 1991). However, the duration of the sexually mature phase was significantly longer in the European than in the African males, and this difference was attributed to the duration of the breeding season (Gwinner, 1991, also see Gwinner, 1996). In A. verbasci, adult seasonal flowervisiting activities are earlier at the southern geographic points (Kato, 1941; Nisimura and Numata, 2001; Matsuno, T., and Numata, H. unpublished; Shintani, Y. personal communication), but the difference could not be attributed to the initial phase or the period of the circannual rhythm. We suggest, therefore, that the geographic differences in flower-visiting activities of adults result from variations in climatic conditions such as temperature from winter to spring.

Pupation was more synchronous under the natural photoperiod and temperature in Osaka than under the natural photoperiod at $20^{\circ} \mathrm{C}$ in the four geographic populations (Figs. $6,7)$. Nisimura and Numata (2003) attributed this difference to the suppression of development by low temperature based on similar results under the natural photoperiod and the results that a change from 25 to $20^{\circ} \mathrm{C}$ caused no or little phase shift in the Osaka population. Such a seasonal pattern is similar to that in most insects in temperate regions with diapause induced by photoperiod (Danks, 1987). However, before reaching any conclusions, it is necessary to examine whether lower temperatures in winter have an effect on the phase of the circannual rhythm and contribute the synchrony of pupation and geographic differences in 


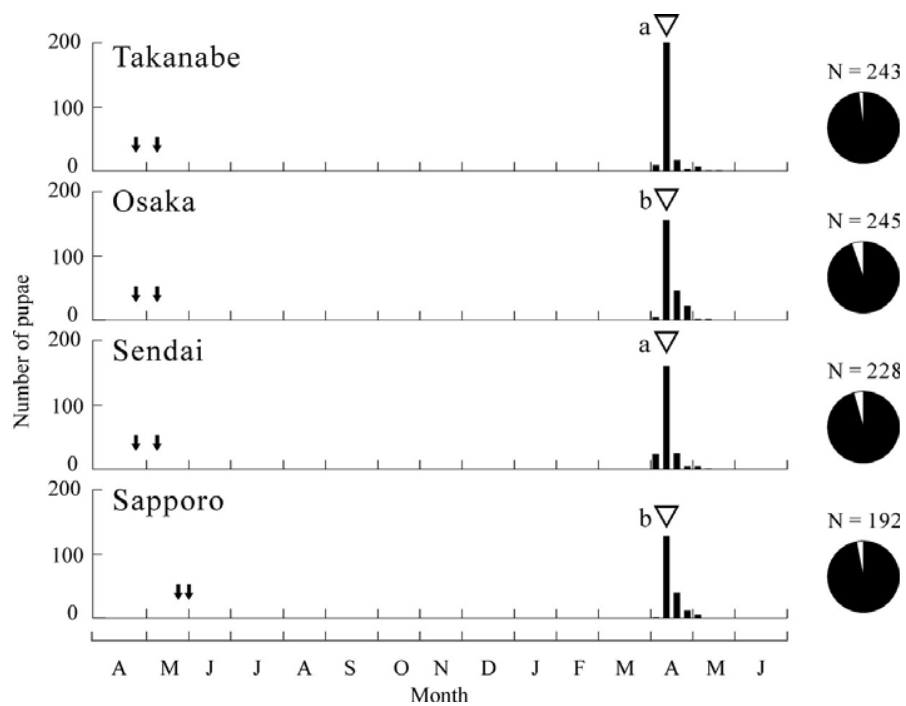

Fig. 7. Pupation under natural photoperiod and temperature in Osaka of Takanabe, Osaka, Sendai, and Sapporo populations in Anthrenus verbasci. In each population, newly hatched larvae were placed to the experimental conditions twice (arrows), and triangles show median values. Significant differences in pupation times are shown as different letters (Steel-Dwass test, $P<0.05$ ). The fan diagrams show the proportion of insects that pupated in a year (black areas, the insects that pupated before 30 June; white areas, the remaining larvae on 30 June). There are no significant differences in the proportions among the four populations (chi-square test, $P>0.05$ ).

adult seasonal activities.

The photoperiodic entrainment for the circannual rhythm of $A$. verbasci was different among the four geographic populations used in the present study. All of the four populations showed clear phase delays when exposed to long-day conditions of LD 15:9 or LD 16:8, compared to continuous short-day conditions of LD 12:12, and the degree of delay in pupation was similar among the four populations. Regarding phase delays, $A$. verbasci quantitatively responded to the photophase duration in intermediate conditions (Figs. 3, 4). These findings are not consistent with the conclusion by Miyazaki and Numata (2009) that a clear phase delay is induced by a photophase longer than a critical value between 13 and $14 \mathrm{~h}$. This is probably because we obtained the results under an intermediate condition of $13.5 \mathrm{~h}$ in the present study.

In species showing photoperiodism, geographically distinct populations often show a cline in the critical daylength. In many insect species, the critical daylength for induction of winter diapause increases toward the higher latitudes, with a difference of approximately $1.0-1.5 \mathrm{~h}$ for every $5^{\circ}$ of latitude (Danilevskii, 1965; Beck, 1980; Danks, 1987; Masaki, 1999). In Japan, for example, the difference in the critical daylength for induction of larval diapause in the rice stem borer, Chilo suppressalis, was shown to be $1 \mathrm{~h}$ per $5.4^{\circ}$ latitude based on a study of 22 geographic populations originating between 31.5 and $43.2^{\circ} \mathrm{N}$ (the broken line in Fig. 5B; Kishino, 1970). The geographic cline in photoperiodism for induction of diapause shows that the critical daylength at the higher latitude corresponds to the daylength in early autumn.
The critical daylength for entrainment of the circannual rhythm in $A$. verbasci was also correlated to the habitat latitude, but the difference was much smaller than that in photoperiodism for induction of diapause (Fig. 5B). Regarding the photoperiodism for induction of diapause, insects must enter diapause earlier in cooler climate regions to avoid production of an additional generation in a season inappropriate for growth and reproduction (Danilevskii, 1965; Beck, 1980; Danks, 1987). Before the autumn equinox, the daylength is longer at higher latitudes. If insects enter diapause before the autumn equinox, the geographic difference in the critical daylength should be longer than the difference in the natural daylength. Therefore, the geographic cline in the critical daylength for induction of diapause is usually steep, e.g., $1 \mathrm{~h}$ for every $5^{\circ}$ of latitude. Larvae of $A$. verbasci do not directly respond to photoperiod to enter diapause, but reset the phase of the circannual rhythm for pupation timing by photoperiod (Nisimura and Numata, 2001, 2003). Unlike other insects that enter diapause by directly responding to photoperiod, $A$. verbasci does not produce an additional generation even if photoperiodic phase-resetting is delayed and larvae remain in an active state longer because pupation occurs approximately half a year after the phase-resetting (Nisimura and Numata, 2001; Miyazaki et al., 2006). In all of the four localities examined in the present study, the critical daylength corresponded to the daylength in September, when the geographic difference in the natural photoperiod is small (Fig. 5B). Thus, the geographic cline in the critical daylength for entrainment of the circannual rhythm was mild.

Geographically distinct subspecies of the stonechat, $S$. t. rubicola, S. $t$. axillaris, and the Siberian subspecies, $S$. $t$. maura, showed different responsiveness to photoperiod for entrainment of the circannual rhythm, when examined under a changing photoperiod simulating that at $47.5^{\circ} \mathrm{N}$ and under a constant photoperiod of LD 12.75:11.25 simulating that at the equator. This difference was discussed in relation to the presence or absence of migration and its timing (Gwinner et al., 1983; Helm and Gwinner, 2001; Helm et al., 2009). However, these subspecies are distributed at distances of several thousand kilometers, and in quite different climates. Therefore, the results found for the stonechat are not discrepant with the small geographic cline in the critical daylength of $A$. verbasci found in the present study, in which all the geographic populations used were within the temperate zone and the largest distance among them was approximately $1500 \mathrm{~km}$.

In accord with our findings of the small geographic difference in the critical daylength and no difference in the initial phase or period of the circannual rhythm in $A$. verbasci, the difference in the pupation time among the four geographic populations was very small under the natural photoperiod in Osaka at $20^{\circ} \mathrm{C}$ (Fig. 6) and absent under the natural photoperiod and temperature in Osaka (Fig. 7). These pupation times are also close to those in an English population kept under natural photoperiod at $20^{\circ} \mathrm{C}$ or natural daylength and temperature in southern England (Blake, 1960). This is in contrast to the results in insects with photoperiodism for diapause induction. For example, a considerable proportion 
of the population of the southern green stink bug, Nezara viridula, dies in autumn without entering diapause in Osaka because this population only recently invaded the area and still has a maladaptive critical daylength (Musolin and Numata, 2003a, b). In contrast, we suggest based on the present results that $A$. verbasci survives and successfully reproduces in different geographic points without changing parameters of its circannual rhythm. Although we still do not know why this species adopts a circannual rhythm for seasonal adaptations, unlike many other insects with usual photoperiodism, this mechanism probably enables $A$. verbasci to be a cosmopolitan species.

However, a geographic cline actually exists in the critical daylength for phase-resetting of the circannual rhythm in $A$. verbasci (Fig. 5B). The circannual rhythm may control certain developmental or physiological parameter(s) not only related to timing of pupation. In fact, this species shows an endogenous rhythm in molting under constant conditions (Blake, 1958). Blake (1958) suggested that the resting period without molting corresponds to larval diapause in other insects. If the circannual phase is related to the physiological status of larvae, such as metabolism or cold hardiness, the cline in the critical daylength would have significance in adaptation to the local climate because temperature decreases earlier in autumn at higher latitudes. Under the natural photoperiod and temperature in Osaka, however, the four geographic populations survived and pupated in the same period (Fig. 7). To clarify the ecological significance of the variations in the critical daylength for the circannual phase resetting and, further experiments, e.g., rearing a southern population in a northern climate, will be needed. Moreover, greater proportions of $A$. verbasci tended to pupate within a year in southern populations under the same conditions (Fig. 6). This also shows an adaptation to local climate, and its ecological significance is an interesting subject for future studies.

\section{ACKNOWLEDGMENTS}

We thank Kazuhiro Tanaka and Yoshinori Shintani for collecting insects, and Elizabeth Nakajima for linguistic corrections. This study was supported in part by a Core Stage Backup Research Grant from Kyoto University.

\section{REFERENCES}

Beck SD (1980) Insect Photoperiodism, 2nd ed. Academic Press, New York

Blake GM (1958) Diapause and the regulation of development in Anthrenus verbasci (L.) (Col., Dermestidae). Bull Entomol Res 49: $751-775$

Blake GM (1959) Control of diapause in an 'internal clock' in Anthrenus verbasci (L.) (Col., Dermestidae). Nature 183: 126127

Blake GM (1960) Decreasing photoperiod inhibiting metamorphosis in an insect. Nature 188: 168-169

Danilevskii AS (1965) Photoperiodism and Seasonal Development of Insects. Oliver and Boyd, Edinburgh

Danks HV (1987) Insect Dormancy: An Ecological Perspective. Biological Survey of Canada (Terrestrial Arthropods), Ottawa

Goldman B, Gwinner E, Karsch FJ, Saunders D, Zucker I, Gall GF (2004) Circannual rhythms and photoperiodism. In "Chronobiology-Biological Timekeeping" Ed by JC Dunlap, JJ Loros, PJ DeCoursey, Sinauer Associates, Sunderland, pp 107-142
Goss RJ (1969) Photoperiodic control of antler cycles in deer. I. Phase shift and frequency changes. J Exp Zool 170: 311-324

Gwinner E (1977) Photoperiodic synchronization of circannual rhythms in the European starling (Sturnus vulgaris). Naturwissenschaften 64: 44-45

Gwinner E (1986) Circannual Rhythms. Springer-Verlag, Berlin

Gwinner E (1991) Circannual rhythms in tropical and temperatezone Stonechats: A comparison of properties under constant conditions. Ökol Vögel 13: 5-14

Gwinner E (1996) Circannual clocks in avian reproduction and migration. Ibis 138: 47-63

Gwinner E, Dittami J (1990) Endogenous reproductive rhythms in a tropical bird. Science 249: 906-908

Gwinner E, Dittami J, Gwinner H (1983) Postjuvenile molt in East African and Central European Stonechats (Saxicola torquata axillaris, S. t. rubicola) and its modification by photoperiod. Oecologia 60: $66-70$

Helm B (2006) Zugunrule of migratory and non-migratory birds in a circannual context. J Avian Biol 37: 533-540

Helm B, Gwinner E (2001) Nestling growth and post-juvenile mould under a tight seasonal schedule in stonechats Saxicola torquata maura from Kazakhstan. Avian Sci 1: 31-42

Helm B, Schwabl I, Gwinner E (2009) Circannual basis of geographically distinct bird schedules. J Exp Biol 212: 1259-1269

Joy JE, Mrosovsky N (1982) Circannual cycles of molt in ground squirrels. Can J Zool 60: 3227-3231

Kato M (1941) The adult activity of the varied carpet beetle Anthrenus verbasci. Oyo-Doubutsugaku Zasshi 13: 76-91 (in Japanese)

Kishino K (1970) Ecological studies on the local characteristics of seasonal development in the rice stem borer, Chilo suppressalis Walker. II. Local characteristics of diapause and development. Jpn J Appl Entomol Zool 14: 1-11 (in Japanese with English abstract)

Masaki S (1999) Seasonal adaptations in insects as revealed by latitudinal diapause clines. Entomol Sci 2: 539-549

Miyazaki Y, Numata H (2009) Responsiveness to photoperiodic changes in the circannual rhythm of the varied carpet beetle, Anthrenus verbasci. J Comp Physiol A 195: 241-246

Miyazaki Y, Numata $H(2010)$ Exhibition of circannual rhythm under constant light in the varied carpet beetle Anthrenus verbasci. Biol Rhythm Res 41: 441-448

Miyazaki Y, Nisimura T, Numata $\mathrm{H}$ (2005) A phase response curve for circannual rhythm in the varied carpet beetle Anthrenus verbasci. J Comp Physiol A 191: 883-887

Miyazaki Y, Nisimura T, Numata $H(2006)$ Phase responses in the circannual rhythms of the varied carpet beetle, Anthrenus verbasci, under naturally changing day length. Zool Sci 23 : 1031-1037

Miyazaki Y, Nisimura T, Numata $H$ (2007) Phase resetting and phase singularity of an insect circannual oscillator. J Comp Physiol A 193: 1169-1176

Miyazaki Y, Nisimura T, Numata H (2009a) Circannual pupation rhythm in the varied carpet beetle Anthrenus verbasci under different nutrient conditions. Entomol Sci 12: 370-375

Miyazaki $Y$, Nisimura T, Numata $H(2009 b)$ A circadian system is involved in photoperiodic entrainment of the circannual rhythm of Anthrenus verbasci. J Insect Physiol 55: 494-498

Monecke S, Saboureau M, Malan A, Bonn D, Masson-Pévet M, Pévet $P$ (2009) Circannual phase response curves to short and long photoperiod in the European hamster. J Biol Rhythms 24: 413-426

Musolin DL, Numata H (2003a) Photoperiodic and temperature control of diapause induction and colour change in the southern green stink bug, Nezara viridula. Physiol Entomol 28: 65-74

Musolin DL, Numata H (2003b) Timing of diapause induction and its life-history consequences in Nezara viridula: Is it costly to expand a distribution range? Ecol Entomol 28: 694-703 
National Astronomical Observatory of Japan (2012) Rising, Setting, Transit of Solar System Bodies. Eco.mtk.nao.ac.jp/cgi-bin/ koyomi/cande/riseset_en.cgi

Nelson RJ, Denlinger DL, Somers DE (eds.) (2010) Photoperiodism: The Biological Calendar. Oxford University Press, Oxford

Nisimura T, Numata $H$ (2001) Endogenous timing mechanism controlling the circannual pupation rhythm of the varied carpet beetle Anthrenus verbasci. J Comp Physiol A 187: 433-440

Nisimura T, Numata $\mathrm{H}$ (2002) Evaluation of the frequency demultiplication hypothesis of the circannual pupation rhythm in the varied carpet beetle Anthrenus verbasci (Coleoptera: Dermastidae). Biol Rhythm Res 33: 255-260
Nisimura T, Numata $\mathrm{H}$ (2003) Circannual control of the life cycle in the varied carpet beetle Anthrenus varbasci. Funct Ecol 17: 489-495

Randall CF, Bromage NR, Duston J, Symes J (1998) Photoperiodinduced phase-shifts of the endogenous clock controlling reproduction in the rainbow trout: A circannual phase-response curve. J Reprod Fertil 112: 399-405

Ward JM Jr, Armitage KB (1981) Circannual rhythms of food consumption, body mass, and metabolism in yellow-bellied marmots. Comp Biochem Physiol A 69: 621-626

(Received October 9, 2012 / Accepted November 13, 2012) 